\title{
Understanding Religion and Social Expectations in Contemporary Muslim Society When Promoting Breastfeeding
}

\author{
Emma Mohamad ${ }^{1}$, Abdul Latiff Ahmad ${ }^{1}$, Samsudin A. Rahim ${ }^{1} \&$ Latiffah Pawanteh ${ }^{1}$ \\ ${ }^{1}$ School of Media and Communication Studies, Faculty of Social Sciences and Humanities, Universiti \\ Kebangsaan Malaysia, Malaysia \\ Correspondence: Emma Mohamad, School of Media and Communication Studies, Faculty of Social Sciences and \\ Humanities, Universiti Kebangsaan Malaysia, Malaysia. E-mail: mirza@ukm.my
}

Received: May 12, 2013 Accepted: June 6, 2013 Online Published: August 1, 2013

doi:10.5539/ass.v9n10p264 URL: http://dx.doi.org/10.5539/ass.v9n10p264

This project is funded by the Ministry of Higher Learning Malaysia under the Fundamental Research Grant Scheme (Research Code: FRGS/1/2012/SS09/UKM/03/1)

\begin{abstract}
The paper aims to examine religious and cultural issues with regards to breastfeeding and explore how this awareness can improve breastfeeding promotion in a contemporary Muslim society. Focusing specifically on Malay women, the study looks at how breastfeeding is being negotiated into women's understanding of modesty in Islam and how this may affect the practice of breastfeeding in public. Using qualitative approach, nine focus groups were conducted among Malay mothers in different parts of Malaysia to explore their experiences breastfeeding in different locations. The respondents were also asked to comment on a breastfeeding picture taken from a local magazine to explore their level of acceptance and responses to image of breastfeeding in the media. It was observed that Malay women were very concerned about Islamic rules with regards to female modesty but often negotiated the sexualized breasts into their overall understanding. The combination of these concerns has discouraged many Malay women to breastfeed in public. The study also found that while many respondents are not comfortable with the idea of having images of Muslim breastfeeding women in the media, their concerns are all related to religious matters. The study suggests that images of Muslim women breastfeeding can and should be used in any promotional items in order to make it a culturally accepted behavior but must also adhere to Islamic rulings.
\end{abstract}

Keywords: Malay, breastfeeding, culture, Islam, health promotion

\section{Introduction}

Breastfeeding is complex not because of its biological nature but because it is deeply embedded within society's social context and cultural practices (Britton, 2009, p. 310). In her article entitled 'Breastfeeding: A natural phenomenon or a cultural construct?' Cathryn Britton (2009) writes about breastfeeding as a social experience (p. 307) and highlights that culture plays an important role in how a woman understands her breasts and their functions in everyday life (p. 310).

Kukla (2006b) argues that the sexualized status inscribed on breasts can contribute to mothers' feeling vulnerable to nurse in public spaces. As she explained, 'Breastfeeding [in public space] opens women to offended, sexualized and even violent and punitive gazes,' (p. 163). This sexualized status inscribed on breasts may also generate other dilemmas such as the designation of public and private space and the notion of domesticity.

However, in Malaysia, sexualized breasts are not the only reason women feel uncomfortable to breastfeed in public. In Islam, women are bound by religious rules that do not allow them to show their skin in the presence of non-Mahram (Note 1) males (except for the face and hands). This has made breastfeeding physically and emotionally difficult for women to perform in public areas and often deters many from breastfeeding in public. With this additional social expectation, Muslim mothers in the $21^{\text {st }}$ century are put into an even more complex predicament. Understanding mothers' dilemmas with regards to this issue could generate a better understanding and improve health practitioners' and health policy makers' approach in future breastfeeding promotion for Muslim mothers / in Muslim society. 
Breastfeeding is mentioned in several verses in the Quran, which include in its very first chapter, Surah Al-Baqarah. The verses in Surah Al-Baqarah emphasized responsibility for parents to provide breast milk to their children during the first two years of life. The verses state:

Mothers suckle their children for two whole years, if they wish to complete the term, and clothing and maintenance must be borne by the father in a fair manner... If by a mutual consent and consultation, the couple wish to wean (the child), they will not be blamed, nor will there be any blame if you wish to engage a wet nurse, provided you pay as agreed in a fair manner. Be mindful of God, knowing He sees everything you do. (Translation from the Quran, Surah Al-Baqarah v.233)

Summary of this verse suggests the importance of the infant's wellbeing and welfare in Islam. Parents should therefore, provide sufficient nutrition to ensure that their children's growth is well protected. Breastfeeding is also discussed further in various hadith (pronouncements of the Prophet) and Islamic teachings. Among other things, Islamic teachings about breastfeeding suggest that:

1) Breastfeeding should be continued even if a couple is divorced. Breastfeeding is a mother's duty but falls on the father's shoulder if they are separated. The biological father should pay for his ex-wife's cost of living (alimony) so that she can continue nursing the child.

2) If it is decided that the biological mother cannot nurse the baby (for example, if she is ill), then a wet nurse may be asked to help. A wet nurse can feed a child only if the mother's milk is not available. The wet nurse then should be paid compensation by the child's biological father.

3) If the mother dies the baby's father should support both the nursing mother and his baby for the period of breastfeeding. The custody of the baby remains in the hands of the nursing mother. If the father dies or does not live at home, his heir must support the mother, thereby allowing her to breastfeed her children.

4) Parents are allowed to wean a child anytime they both feel it is appropriate as long as the decision is made in agreement by both parents and does not jeopardise the child's health.

(The Quran and Hadith from Al Bukhari Muslim) (Note 2)

Although breastfeeding is given much emphasis in the Quran and Islamic teachings, there is not a specific rule about the exact time to wean a child as long as his/her wellbeing is not being compromised. It is therefore not considered a sin if both parents decided to wean off their baby from the breasts. However, it is important to remember that the teachings in the Quran had long existed before formula milk (or any other scientific innovation of breast milk substitute).

\section{Methodology}

Nine focus groups were conducted among Malay mothers throughout peninsular Malaysia. Only Malay mothers were included in the focus groups as to concentrate on issues that are exclusively related to Islam. The focus groups were conducted in six different states (out of 14 states in Malaysia). The women ranged from age 24 to 44 (within child bearing age), with the majority falling between the ages of 25 to 30 years old. A general description of the focus group participants is given in table 1. The study limited focus groups to just mothers of children below the age of two as all mothers in this category would still be breastfeeding or formula feeding (or both). 
Table 1. Distribution of focus groups

\begin{tabular}{|c|c|c|c|c|c|c|}
\hline \multirow{3}{*}{$\begin{array}{l}\text { Focus } \\
\text { Group } \\
\text { Focus } \\
\text { Group 1 }\end{array}$} & \multirow{3}{*}{$\begin{array}{l}\text { Location } \\
\begin{array}{l}\text { Selangor } \\
\text { (City) }\end{array}\end{array}$} & \multirow{3}{*}{$\begin{array}{l}\text { Social / Occupational Background } \\
\text { Young Professionals with } \\
\text { Bachelor/Master degree Qualification }\end{array}$} & \multicolumn{3}{|c|}{$\begin{array}{l}\text { Name, age and current } \\
\text { infant feeding choice }\end{array}$} & \multirow{2}{*}{$\begin{array}{c}\text { Total } \\
\text { participants } \\
4\end{array}$} \\
\hline & & & Qaseh & 29 & $\mathrm{BF}$ & \\
\hline & & & Rania & 29 & $\mathrm{BF}$ & \\
\hline & & & Hannah & 29 & $\mathrm{BF}$ & \\
\hline & & & Mila & 29 & $\mathrm{FF}$ & \\
\hline \multirow{5}{*}{$\begin{array}{l}\text { Focus } \\
\text { Group } 2\end{array}$} & \multirow[t]{5}{*}{ Johor (City) } & \multirow{5}{*}{$\begin{array}{l}\text { Working class family - Stay at home } \\
\text { moms and working mothers with High } \\
\text { School / College Qualification }\end{array}$} & Mimi & 38 & $\mathrm{BF}$ & 5 \\
\hline & & & Julita & 39 & $\mathrm{FF}$ & \\
\hline & & & Dina & 34 & $\mathrm{BF}$ & \\
\hline & & & Zaqyah & 34 & $\mathrm{NF}$ & \\
\hline & & & Lana & 33 & $\mathrm{FF}$ & \\
\hline \multirow{4}{*}{$\begin{array}{l}\text { Focus } \\
\text { Group } 3\end{array}$} & \multirow{4}{*}{$\begin{array}{l}\text { Selangor } \\
\text { (City) }\end{array}$} & \multirow{4}{*}{$\begin{array}{l}\text { Young professionals working at a local } \\
\text { university }\end{array}$} & Lina & 29 & $\mathrm{MF}$ & 4 \\
\hline & & & Sarah & 29 & $\mathrm{FF}$ & \\
\hline & & & Zahra & 37 & $\mathrm{BF}$ & \\
\hline & & & Joyah & 29 & $\mathrm{FF}$ & \\
\hline \multirow{4}{*}{$\begin{array}{l}\text { Focus } \\
\text { Group } 4\end{array}$} & \multirow{4}{*}{$\begin{array}{l}\text { Perak } \\
\text { (Town) }\end{array}$} & \multirow{4}{*}{$\begin{array}{l}\text { Young administrative staff working at a } \\
\text { teacher's college }\end{array}$} & Nani & 29 & $\mathrm{FF}$ & 4 \\
\hline & & & Cinta & 30 & $\mathrm{BF}$ & \\
\hline & & & Damia & 31 & $\mathrm{BF}$ & \\
\hline & & & Acha & 26 & $\mathrm{BF}$ & \\
\hline \multirow{6}{*}{$\begin{array}{l}\text { Focus } \\
\text { Group } 5\end{array}$} & \multirow{6}{*}{$\begin{array}{l}\text { Pahang } \\
\text { (Town) }\end{array}$} & \multirow{6}{*}{$\begin{array}{l}\text { Working class family. Stay at home } \\
\text { moms and working moms, some with } \\
\text { university degree qualifications }\end{array}$} & Khayra & 33 & $\mathrm{MF}$ & 6 \\
\hline & & & Kimie & 29 & $\mathrm{FF}$ & \\
\hline & & & Bedah & 29 & $\mathrm{FF}$ & \\
\hline & & & Layla & 24 & $\mathrm{FF}$ & \\
\hline & & & Marissa & 29 & FF & \\
\hline & & & Yasmin & 33 & $\mathrm{FF}$ & \\
\hline \multirow{4}{*}{$\begin{array}{l}\text { Focus } \\
\text { Group } 6\end{array}$} & \multirow{4}{*}{$\begin{array}{l}\text { Perak } \\
\text { (Rural) }\end{array}$} & \multirow{4}{*}{$\begin{array}{l}\text { Working moms at two local university } \\
\text { state branches. All with University } \\
\text { bachelor degree qualifications }\end{array}$} & Naema & 35 & $\mathrm{FF}$ & 4 \\
\hline & & & Aminah & 29 & $\mathrm{BF}$ & \\
\hline & & & Verra & 29 & $\mathrm{MF}$ & \\
\hline & & & Damia & 31 & MF & \\
\hline \multirow{3}{*}{$\begin{array}{l}\text { Focus } \\
\text { Group } 7\end{array}$} & \multirow{3}{*}{$\begin{array}{l}\text { Kuala } \\
\text { Lumpur } \\
\text { (City) }\end{array}$} & \multirow{3}{*}{$\begin{array}{l}\text { Working moms with university bachelor } \\
\text { degree qualifications }\end{array}$} & Rabiah & 29 & MF & 3 \\
\hline & & & Iza & 29 & $\mathrm{FF}$ & \\
\hline & & & Maria & 29 & $\mathrm{BF}$ & \\
\hline \multirow{6}{*}{$\begin{array}{l}\text { Focus } \\
\text { Group } 8\end{array}$} & \multirow{6}{*}{$\begin{array}{l}\text { Selangor } \\
\text { (City) }\end{array}$} & & Sofea & 40 & $\mathrm{FF}$ & 6 \\
\hline & & moms/ teachers/working moms, some & Latiffah & 28 & $\mathrm{FF}$ & \\
\hline & & & Heidi & 27 & $\mathrm{FF}$ & \\
\hline & & & Lola & 41 & $\mathrm{FF}$ & \\
\hline & & & Tina & 37 & $\mathrm{BF}$ & \\
\hline & & & Orked & 34 & $\mathrm{NF}$ & \\
\hline Focus & Kelantan & Stay at home moms with low income & Mas & 24 & MF & 4 \\
\hline Group 9 & (Rural) & family & Yusra & 38 & MF & \\
\hline & & & Bunga & 24 & MF & \\
\hline & & & Fatima & 39 & $\mathrm{BF}$ & \\
\hline
\end{tabular}

Focus group generates participants' interactions, which then result in better understanding of audience's insights in the social processes involved in knowledge production, explained through their own language and motivation (Kitzinger, 1994; Wilkinson, 1998). This interaction is important as mothers can share their experiences and explore issues they face with breastfeeding in public. In the focus groups, research participants were encouraged to talk about their own experiences breastfeeding / formula feeding. To stimulate and diversify the discussion, 
focus group respondents were shown a breast pump advertisement featuring a picture of a breastfeeding baby in Figure 1. This advertisement came out several times in Pa\&Ma (a local parenting magazine) in 2008 and 2009. In the focus groups, research participants were encouraged to relate the advertisement to their personal breastfeeding experiences or experiences with other women breastfeeding.

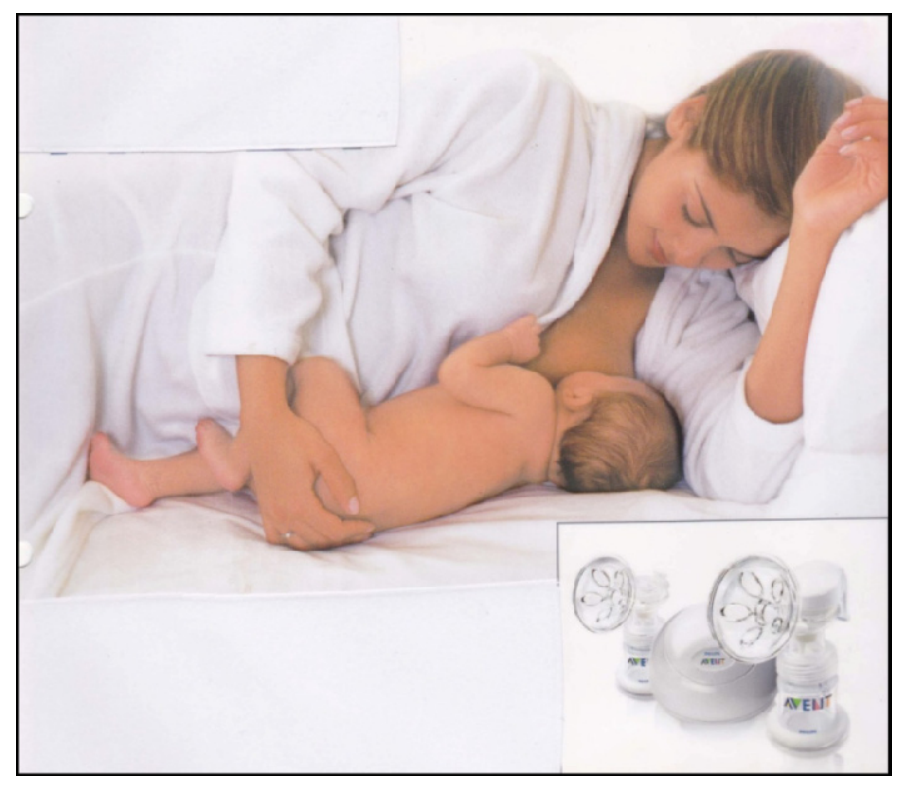

Figure 1. Breast pump advertisement prompt used in the focus groups

In research analysis, focus group mothers were identified according to their current feeding practice (for their youngest child) at the time of this research was conducted. It should be noted that these mothers have different infant feeding experiences with each of their children. All the research participants in the focus groups had however, experienced breastfeeding (even if it was only for the first few days after birth).

\section{Results and Discussion}

Overall, the study observed that mothers who felt uncomfortable breastfeeding in public would try as much as possible to avoid doing so. In one focus group all respondents agreed to this:

Layla (24, FF): If a baby is more than two months old, it is probably better to feed them with formula milk when we are out.

Khayra (33, FF): You can breastfeed in the car before you reach your destination. Make sure the baby is full before you go out. And make sure you bring formula milk just in case.

Yasmin (33, FF): Yes, it is better to have both.

(Focus Group 5, Town)

For mothers who do breastfeed in public many exercise self-regulation and are very cautious of their surroundings. It was observed that women tried to keep breastfeeding discreet and would rather people not knowing them breastfeeding. Respondents mentioned experiences breastfeeding in prayer rooms (Note 3), fitting rooms, under the table, behind bushes and in the car. When explaining their actions, many of these women responded to the social meanings attached to breasts, which are sexual and private. Furthermore, because Muslim women are required to cover their full body, all respondents felt the need to breastfeed in a discreet manner, in order to uphold their integrity and modesty as Muslim women. Yet, at the same time women also responded to the sexual connotations of breasts and this also affected how they feel and response to their experiences breastfeeding in public. One respondent for example said,

"People are always curious when they see a woman breastfeeding in public places. Both men and women... they would want to take a closer look. Of course that would make me feel uncomfortable. But I would just carry on breastfeeding.... People would give you a certain look, like they are judging you or something." 
However, not all respondents felt the need to remove themselves from public space when breastfeeding. Exclusive breastfeeding mom Qaseh for example said,

"I'm the type of person who doesn't really care about what others would say about me. It's not like I'm committing a sin. I'm doing a good thing, so I don't really care."

(Qaseh, 29, BF, Focus Group 1, City)

Another member of the same focus group, Rania also concurred, 'If you really have to breastfeed then just do it. You can do it anywhere, it doesn't matter. What matters is your baby,' (Rania, 29, BF, Focus Group 1, City).

The study also found that supportive surroundings may encourage women to breastfeed in public. One particular focus group (involving mothers living in a remote district village) demonstrated this:

Yusra (38, MF): I breastfeed anywhere I can. If he's crying and he wants to feed, I'd give him straight away. I don't feel ashamed or anything. Of course people will look, but that's normal. People understand. That's just how things are when you have babies.

Mas (24, MF): Everyone would understand the need to breastfeed. Even a teenager would ask me to breastfeed if he sees my baby crying. So there is nothing to be ashamed of.

Yusra (38, MF): That's right. Whether it is here, or in the city... if he's crying, I'd feed him straight away.

(Focus Group 9, Rural)

This group of women suggested that breastfeeding in public can be accepted as a norm in a Muslim community and is not always seen as a 'deviant' behavior. However, this was the only group in the study that responded positively about their surroundings. It should be noted that breastfeeding is more common among mothers in Malay rural communities because of the socio-economy factor. Formula milk can be costly and most families living in villages earn below than average income (average monthly income of less than USD300). It is therefore, very common for mothers in the rural areas to breastfeed their infants.

In this particular focus group, research participants felt comfortable and empowered to breastfeed in public because it is a cultural norm to do so and therefore, is accepted as a normal practice in the community. There might be an important rural-city differences observed here which suggested that social surroundings can play a role to encourage (or challenge) mothers to breastfeed in public areas. But more importantly, this may also suggest that modernity has allowed sexual meanings of breasts to assimilate so saliently in contemporary Muslim society and this has changed the way Malays understand breastfeeding. Although respondents talked about how Islam encourages breastfeeding, this did not necessarily empower them to breastfeed in public.

Mabilia (2005) argues that breastfeeding is able to regulate social behaviors of a community through multiple ways of understanding and experiencing cultural meanings. Islamic regulation regarding modesty and the female aurat positions breasts as object of inscrutability and is isolated from the public realm. Women's concern over the female aurat is one of the reasons leading to the privacy and modesty of their behavior in public space. Breastfeeding in public (whether or not the breasts are exposed to others) challenges this reasoning and social acceptance of behaviors in public.

For most cases within my sample (which was mostly city/town based) breastfeeding in public continues to be seen as inappropriate. So much so, that in some cases, people would express verbal disapprovals and even nasty comments to mothers for breastfeeding in public. One participant told her story,

“A man once said to me: 'Aren't you ashamed of yourself? Don't you have somewhere else to sit?' I mean what was I to do? I had a crying baby in my arms so I had no choice but to breastfeed."

$$
\text { (Dina, 34, BF, Focus Group 2, City) }
$$

On several occasions, respondents described negative experiences involving 'male sexual gazes' upon them breastfeeding in public. Acha explained this, 'They (the men) would look at you in the most perverted way. They stare at you as if they are about to pounce on you,' (Acha, 26, BF, Focus Group 4, Rural). This statement reinforces the idea that breasts (even when during breastfeeding) are seen/understood as sexual objects.

As for division of public and private space, it was observed that location does not always matter, but depending on how mothers understood the space, as well as the people who occupied that space. A participant demonstrated this,

"I was breastfeeding my son in a nursing room at a shopping complex. A couple then entered the room.

The wife started to breastfeed. The husband decided to stay and wait for his wife to finish. I was 
horrified! There was a sign in the room saying that men are not allowed in but he just couldn't be bothered. I was so annoyed, I mean... seriously? There was no curtain to separate us and there I was breastfeeding in front of him. He looked at me... Not in a perverted way but still... he made me feel uncomfortable."

(Aminah, 29, BF, Focus Group 6, Rural)

The transformation from 'private' to 'public' space prompted by male presence may suggest empowerment of patriarchal dominance and the diminishing of maternal control in public space. It was also observed again in this example that the respondent identified her breasts as sexual objects in front of men and therefore the nurturing role has taken a secondary meaning. Similar response was also observed here: "I have never breastfeed openly in front of other people. Not even in front of my eldest. He is ten. I would breastfeed in my bedroom," (Zahra, 37, BF, Focus Group 3, City). Another mother however, felt absolutely fine with breastfeeding in front of her own children, although she also implied that it might be inappropriate for boys who are not used to looking at breasts as a nurturing organ.

"I do not think there would be any problem if the mother has introduced them with breastfeeding since young. I have no problem at all with my boys. But there might be a problem if the child has never been breastfed before."

(Maria, 29, BF, Focus Group 7, City)

Overall, the study found that mothers who do breastfeed in public felt quite empowered through their experience. Nonetheless, mothers would continue to be discreet and not allow their breasts to be seen by others. When asked about their experiences breastfeeding in public, one research participant said,

"I breastfeed in public all the time... I just sit down and breastfeed. After all I use my nursing blanket so people couldn't see what I am doing anyway."

(Rabiah, 29, MF, Focus Group 9, City)

There are also mothers who would find a more discreet place to breastfeed. Aminah for instance said, "I once did it in KFC. I found a suitable place, a secluded area, behind a partitioned wall. Then I faced the wall and breastfed," (Aminah, 29, BF, Focus Group 6, Rural).

Overall, it was observed that mothers have different experiences with breastfeeding in public. The border between public and private is a grey line defined by mothers themselves through their negotiation with modesty, Islamic regulations of aurat, interpretation of space and their relationship with others.

There are mothers who felt empowered breastfeeding in public, while others felt ashamed. Although some women do breastfeed in public, breastfeeding continued to be kept discreet. Participants' discussion and definition on public and private space depended very much on mothers' interpretation of space. This was influenced by many aspects, but mainly determined by the people occupying that space.

\section{Division of Space: Watching Breastfeeding Bodies in the Media}

Earlier in the method section it was mentioned that the study had used a breast pump advertisement as a prompt in the focus groups. This part of the paper will specifically explore the variety of responses received from the prompt, particularly participants' responses to having breastfeeding images in the Malaysian media.

Mothers' immediate responses when presented with this advertisement focused on discussions of suitability in the media. Many respondents questioned the suitability of the image in the Malaysian media because of the 'exposed breast', even though it was not entirely showing. Some participants even suggested that the advertisement was taken from an international magazine; an indication of the lack of breastfeeding images or the 'unsuitability' of breastfeeding pictures in the Malaysian media. It was also interesting to observe that participants were concerned with how Malaysian audience would respond to the breastfeeding image, as opposed to their own personal opinion as media audience. All research participants suggested that it was important to take into consideration the opinion of the general public when evaluating the suitability of images in the media. This included respecting social expectations, mainly related to Islamic rules on modesty and aurat.

In most focus groups, research participants expressed their reluctance towards the idea of showing breastfeeding picture in the Malaysian media. For example, in one focus group, mothers discussed this:

Julita (39, FF): I don't think Malaysian can accept this picture (in the media). I mean, I know that breastfeeding is a good thing but you don't have to show off the breasts.

Mimi (38, BF): This picture is unacceptable. She should cover up. 
Julita (39, FF): It's the way she is lying down.

Mimi (38, BF): Yes, it is too revealing.

(Focus Group 2, City)

There are also participants in the focus groups who preferred the media to show pictures of non-Malays. Maria example explained,

"If the model is white, it should be all right. But if she is a Malay woman... I think I would feel a little offended. I don't know... I guess some people can accept it. But for some people like me, would feel that it is inappropriate."

(Maria, 29, BF, Focus Group 7, City)

Mothers in another focus group suggested that it was not suitable to use Malaysian women in breastfeeding images; even when it was mentioned later in the discussion that people in the breastfeeding picture are 'just models', and that their race should not matter:

Verra (29, MF): I don't mind if the model is not Malaysian.

Aminah (29, BF): Yes, not even a Malaysian Chinese. This advertisement is fine because the model is white.

Moderator: Would the race affect your attitudes towards breastfeeding?

Verra (29, MF): It wouldn't. She's just a model. But because she's breastfeeding, she did make me feel like breastfeeding too. Even when she is not Malay.

(Focus Group 6, Rural)

Only women who were truly passionate about normalizing breastfeeding would agree to show images of Malay women breastfeeding in the media. Even so, they would still express their concern over the potential exposure of aurat, and that they would prefer to have a non-Muslim model for breastfeeding advertisements. There is definitely a point of tension between normalizing breastfeeding versus that what is seen to be culturally/religiously unacceptable. The challenge is to normalize breastfeeding by showing it as everyday routine, but at the same time respecting the rules of aurat.

There were some similarities in the way research participants treat breastfeeding bodies in the media and in real space. In some focus groups, participants mentioned for example, feeling uncomfortable when watching breastfeeding bodies in the media, especially in male presence. It was clear from the discussion that sexual connotations of breasts deterred them from accepting breastfeeding pictures in the media.

Kimie (29, FF): It is not suitable for everyone. If a man saw this on the TV they would definitely get aroused and they might want to continue watching. If I was watching... and there was another man sitting in the same room, I would feel embarrassed.

Bedah (29, FF): If it is just us women watching this advert, I would feel okay. Breastfeeding is a great thing. But if I watched this with a man, like my husband or my father, I think I would feel uncomfortable.

Layla (24, FF): I would feel ashamed.

Marissa (29, MF): We are different from men.

Khayra (33, FF): We experience it ourselves (breastfeeding).

Yasmin (33, FF): Maybe married men are okay with it. But not single men... This is not suitable for their viewing. They don't feel embarrassed watching it, but we would.

Moderator: Why would you be?

Yasmin (33, FF): Because we understand what it means to them (sexual), that's why we feel embarrassed watching it with them.

(Focus Group 5, Town)

The discussion above is interesting because of the way Yasmin relate her embarrassment watching breastfeeding pictures (in male presence) as though she herself sees the breasts as sexual, despite acknowledging them as maternal.

However, some women suggested that fathers would view lactating breasts as maternal and not sexual objects. 
Mothers in the following focus group discussed this:

Nani (29, FF): I think married men perceive breastfeeding differently. Single men understand breasts as sexual and they are ignorant about the original function of breasts (for breastfeeding). But for fathers, they don't see breasts like that. For them, breastfeeding is normal, so they would be able to accept breastfeeding images.

Cinta (30, BF): Single men are fascinated by breasts because they have never seen real breasts before. (Note 4)

\section{(Focus Group 4, Town)}

The ways in which mothers treat breastfeeding bodies in the media are similar to how they would response towards breastfeeding bodies in person. Women negotiate cultural and religious boundaries as well as social discourses of breasts as sexual and maternal when discussing breastfeeding in public. Similar to mothers' discussion about public and private, some women mentioned how breastfeeding pictures might be tolerated if the pictures appeared in specialist media as opposed to in general media. One focus group discussed this:

Mila (29, FF): I think it would be alright if it was in a parenting magazine, like in Pa\&Ma.

Rania (29, BF): Yes, that would be more suitable than in newspapers.

\section{(Focus Group 1, City)}

There are also mothers (mostly breastfeeding mothers such as Aminah, Verra and Qaseh) who argued that breastfeeding pictures should be shown in the media. These women believed that exposing breasts was not really an issue, but the way people understand them that matters. As one respondent illustrated this,

"There are many other advertisements out there showing more flesh than this. This picture is merely showing a mother and her baby. I can't see anything wrong with this advert."

\section{(Verra, 29, FF, Focus Group 6, Rural)}

It was interesting to hear the different views and negotiations participants have with the locations of breasts images in the media. Mothers in focus group 5 for example felt that it was the sexual connotations of breasts that disrupt the meanings of breastfeeding. However, it can also be argued that the maternal connotation of breasts that was seen inappropriate to be displayed in public discourse (because the lactating breasts signify meanings other than sexual).

Even though many mothers advocated for more breastfeeding awareness in the media, some still conformed to the sexual meanings of breasts. This has led them feeling hesitant towards portrayal of lactating breasts in the media. The sexual connotation of breasts in a way influenced mothers' understanding of the social expectations of breasts, particularly when, where and how breasts should be shown in the media. Significantly, the way people perceived breastfeeding in the media is also influenced by society's norm, codes and convention.

\section{Concluding Notes}

It was observed that Muslim women's responses to public breastfeeding are slightly different from Western women who talks of respect and modesty and see public breastfeeding as signifying that they are sexually available women. Findings in this study suggested that religion plays a significant role in the (re)construction of breastfeeding culture in Malay society. Religion is an important element in a society where faith and obedience to God are fundamental to their culture and daily lives, a society like the Malays. Findings in this research suggested that mothers tend to (but not necessarily) overlap Islamic teachings when discussing issues surrounding breastfeeding. This is particularly observed in their discussion about aurat and modesty in different spaces. Yet, it was also observed that the Western meanings of breasts as sexual objects also influenced how Malay women understand their breasts and how they see public exposure of breasts when breastfeeding.

The study suggests that modesty through Islamic rulings of aurat and modern sexual interpretation of breasts play an important role in participants' understanding of breastfeeding in public and in the media. In particular, mothers recognise their responsibilities as Muslim women (through the rules of aurat) which shape feelings of modesty and the way they look at space (both media and real space). At the same time, they also recognize the current discourse of sexualized breasts. Lactating breasts and breastfeeding bodies seemed to disrupt sexual connotations of breasts. Therefore breastfeeding needs to be managed and 'disciplined' according to behaviors and manners in which it is required in society. Simultaneously, although mothers were concerned that breastfeeding might be seen as sexual, it was not just the sexual meanings of breast that necessarily bothered them, but also the social and cultural expectations for women to guard their modesty and aurat from the public 
view.

Additionally, from the focus groups it was notable that there was a distinction between responses from the city/town based mothers and the rural mothers regarding breastfeeding in public. Women in the rural group were very open about breastfeeding in public. They had positive experiences breastfeeding in public places and felt strongly that the society is supportive of breastfeeding mothers. On the other hand, most women in the city groups felt uncomfortable with breastfeeding in public and felt that society is not ready to accept it in public discourse. This was supported with some of their own negative experiences breastfeeding in public.

The study suggests that there are added challenges faced by breastfeeding advocates to normalize breastfeeding in a Muslims society. Unlike Western women, Muslim women cannot challenge the sexual discourse of breasts by breastfeeding openly in public (showing skin). And as the study has shown, many women continue to keep breastfeeding (even in public) discreet. In order to change this, the society as a whole needs a paradigm shift. As outlined in one focus group, support from social surroundings can make a difference and empower women to breastfeed in public (shown by mothers in group 9). To make breastfeeding in public a norm in Malaysia, health campaigns and the media should portray Malay/native women, not Western women. This is to break the current social discourse (breasts as sexual objects and breastfeeding in public as deviant behavior). However, in so doing, images should also adhere to Islamic rules.

Although the study is limited to Malay women, findings may help future research in areas of health education and also cross-cultural studies on infant feeding practices. For example, understanding Muslim women's concerns about aurat and their reactions to breastfeeding bodies in the media may be useful for future breastfeeding campaigns. In addition, healthcare practitioners worldwide can improve their practical approach when promoting, or giving physical support for Muslim women to breastfeed. The study could also be useful in future policy making in relations to maternity leave and breastfeeding at the workplace.

\section{References}

Bartlett, A. (2005a). Breastwork: Rethinking Breastfeeding. Sydney: UNSW Press.

Bartlett, A. (2005b). Maternal sexuality and breastfeeding. Sex Education, 5(1), 66-77. Retrieved from $\mathrm{http} / / / \mathrm{www}$.mamsie.org/wp-content/librarypapers/A.Bartlett+\%27Maternal+Sexuality+and+Breastfeeding\% 27+Sex+Education+2005.pdf http://dx.doi.org/10.1080/146818142000301894

Bentley, M., Dee, D., \& Jensen, J. L. (2003). Breastfeeding among low income, African-American women: Power, beliefs, and decision making. The Journal of Nutrition, 133(1), 305-309. Retrieved from http://jn.nutrition.org/content/133/1/305S.full.pdf

Blum, L. M. (1999). At the breast: Ideologies of breastfeeding and motherhood in the contemporary United States. Boston: Beacon Press.

Britton, C. (2009). Breastfeeding: A natural phenomenon or a cultural construct. In C. Squire (Ed.), The social context of birth (pp. 305-317). Oxford: Radcliffe.

Carter, P. (1996). Breast feeding and the social construction of heterosexuality, or 'What breasts are really for.' In J. Holland \& L. Adkins (Eds.), Sex, sensibility, and the gendered body (pp. 99-119). London: Macmillan.

Dettwyler, K. A., \& Stuart-Macadam, P. (Eds.). (1995). Breastfeeding: Biocultural perspectives. New York: Aldine de Gruyter.

Forbes, G., Adams-Curtis, L., Hamm, N., \& White, K. (2003). Perceptions of the woman who breastfeeds: The role of erotophobia, sexism, and attitudinal variables. Sex Roles, 49, 379-388. Retrieved from http://link.springer.com/content/pdf/10.1023\%2FA\%3A1025116305434.pdf http://dx.doi.org/10.1023/A:1025116305434

Frankland, J., \& Bloor, M. (1999). Some issues arising in the systematic analysis of focus group materials. In R. Barbour, \& J. Kitzinger (Eds.), Developing focus group research: Politics, theory and practice. London: Sage. http://dx.doi.org/10.4135/9781849208857.n10

Hausman, B. L. (2003). Mother's milk: Breastfeeding controversies in American culture. London: Routledge.

Henderson, L., McMillan, B, Green, J. M., \& Renfrew, M. J. (2011). Men and infant feeding: perceptions of embarrassment, sexuality, and social conduct in white low-income British men. BIRTH, 38(1), 61-70. http://dx.doi.org/10.1111/j.1523-536X.2010.00442.x

Kitzinger, J. (1994). Challenging sexual violence against girls: A social awareness approach. Child Abuse Review, 3(4), 246-248. http://dx.doi.org/10.1002/car.2380030404 
Kukla, R. (2006a). Introduction: Maternal Bodies. Hypatia, 21(1), 7-9. http://dx.doi.org/10.1111/j.1527-2001.2006.tb00960.x

Kukla, R. (2006b). Ethics and ideology in breastfeeding advocacy campaigns. Hypatia, 21(1), 157-180. http://dx.doi.org/10.1111/j.1527-2001.2006.tb00970.x

Mabilia, M. (2005). Breastfeeding and sexuality: Behaviour, beliefs and taboos among the Gogo mothers in Tanzania. Oxford: Berghahn Books.

Stearns, C. A. (1999). Breastfeeding and the good maternal body. Gender and Society, 13(1), 308-325. http://dx.doi.org/ 10.1177/089124399013003003

Wall, G. (2001). Moral constructions of motherhood in breastfeeding discourse. Gender and Society, 15(4), 590-608. Retrieved from http://www.jstor.org/stable/3081924 http://dx.doi.org/10.1177/089124301015004006

Ward, L. M., Merriwether, A., \& Caruthers, A. (2006). Breasts Are for Men: Media, Masculinity Ideologies, and Men's Beliefs about Women's Bodies. Sex Roles: A Journal of Research, 55(9-10), 703-714. http://dx.doi.org/ 10.1007/s11199-006-9125-9

Wilkinson, S. (1998). Focus group methodology: A review. International Journal of Social Research Methodology, 1, 181-203.

Wolf, J. (2001). Don't kill your baby: Public health and the decline of breastfeeding in the nineteenth and twentieth centuries. Columbus: The Ohio State University Press.

Young, K. (1990). American conceptions of infant development from 1955 to 1984: What the experts are telling parents. Child Development, 61, 17-28. Retrieved from http://www.jstor.org/stable/1131044

\section{Notes}

Note 1. Mahram / Muhrim are those who are within the prohibited degrees of marriage (such as family members). This includes blood- related uncles / aunts, parents-in-law and milk siblings.

Note 2. Islamic teachings are based on two pillars of knowledge, the Quran and Hadith. Hadith is a collection of sayings and deeds of Prophet Muhammad, also known as the sunnah. Bukhari lived a couple of centuries after the Prophet's death and worked extremely hard to collect his hadith. Each report in his collection was checked for compatibility with the Quran. Bukhari's collection is recognised by the majority of Muslim community as one of the most authentic collections of the Sunnah of the Prophet.

Note 3. Mosques or prayer rooms have designated space for women and separated by curtains/partition/wall.

Note 4. Pre-marital sex is prohibited in Islam.

\section{Copyrights}

Copyright for this article is retained by the author(s), with first publication rights granted to the journal.

This is an open-access article distributed under the terms and conditions of the Creative Commons Attribution license (http://creativecommons.org/licenses/by/3.0/). 